Rev. Saúde públ, S. Paulo, 26(3): 203-5, 1992

\title{
Infecção chagásica transfusional detectada no programa de controle da doença de Chagas no Estado de São Paulo (Brasil)*
}

\author{
Transfusional chagasic infection detected during the execution of a program for \\ the control of Chagas' disease in the State of S. Paulo (Brazil).
}

\section{Dalva Marli Valério Wanderley*t, Maria Esther de Carvalho*, Ézio Mantegazza**, Sueli Yasumaru*t, Luiz Carlos Barradas Barata}

\begin{abstract}
WANDERLEY, D.M.V. et al. Infecçāo chagásica transfusional detectada no programa de controle da doença de Chagas no Estado de São Paulo (Brasil). Rev. Saúde públ., S. Paulo, 26: 203-5, 1992. O sistema de vigilância da doença de Chagas no Estado de São Paulo propõe investigação minuciosa da presença de triatomíneos nos domicilios, que inclui o controle sorológico de populações moradoras em unidades domiciliares associadas a focos potenciais de triatomíneos vetores. Nos últimos anos tem-se observado que os indivíduos sorologicamente reagentes distribuem-se em faixas etárias acima de 19 anos, sendo que as investigaçōes de casos mostraram que estes adquiriram a infecçăo no Estado de Såo Paulo, no passado ou em outros Estados onde a endemia ainda ocorre. Recentemente, um caso de uma criança de oito anos de idade, residente na Regiảo de Sorocaba (SP), mostrou-se sorologicamente reagente (título igual a 128 - IgG - por meio da Reação de Imunofluorescência Indireta). Pela investigação epidemiológica revelou tratar-se de caso transfusional, cujo doador, sorologicamente reagente, forneceu elementos suficientes para explicar a origem da infecção. Observou-se que este doador já havia doado sangue em mais de uma oportunidade, sem que se tivesse descoberto tratar-se de portador de infecção chagásica. Concluiu-se pela necessidade de implantação de sistema de atendimento de pacientes sorologicamente reagentes, tendo em vista horizontalizar atividades de saúde pública.
\end{abstract}

Descritores: Tripanossomose sul-americana, transmissão. Transfusão de sangue, efeitos adversos.

\section{Introdução}

O controle da transmissão vetorial da doença de Chagas no Estado de São Paulo teve início em 1950 e após duas décadas de ações contínuas, os indicadores entomológicos e de prevalência da endemia na população humana apontavam êxito nesse sentido. Com o controle dos vetores domiciliados - Triatoma infestans espécies ditas "secundárias" na transmissão como T. sordida e Panstrongylus megistus passaram a assumir importância crescente à medida que se constatava o crescimento destas espécies nas coletas efetuadas no ambiente domiciliar.

Assim, foi proposto para a zona rural do Estado de São Paulo um sistema de vigilância da doença de Chagas, que visasse não só a garantir os resultados alcançados pelas medidas de controle, como também aumentar a eficiência

* Trabalho apresentado na VI Reuniảo Anual de Pesquisa Aplicada em Doença de Chagas, Uberaba, 1989.

** Superintendência de Controle de Endemias (SUCEN) São Paulo, SP - Brasil.

Separatas/Reprints: D.M.V. Wanderley - Rua Paula Souza, 166 - 01027 Sảo Paulo, SP - Brasil.

Publicacão financiada pela FAPESP. Processo Saúde Coletiva 91/4994-0. das açōes de intervenção.

Desta forma, qualquer presença de triatomíneos nos domicilios se constitui num foco e como tal deve ser investigada. Neste particular, tem sido realizada pesquisa de anticorpos antiTrypanosoma cruzi no sangue dos moradores das casas com presença demonstrada de: a) Triatoma infestans; b) triatomineos hematófagos em que se tivesse detectado a presença de sangue humano; c) triatomíneos hematófagos positivos para $T$. cruzi. Todos os pacientes sorologicamente positivos devem ser investigados epidemiologicamente devendo sor determinado o possível local de transmissão. A técnica sorológica escolhida foi a Reação de Imunofluorescência Indireta (RIFI) $1,3,4$.

Entre 1984 a 1987 foi observada, na população selecionada segundo o critério descrito, positividade sorológica de ordem de $3,5 \%$ no Estado como um todo. De acordo com a região de onde procediam os pacientes, tal percentagem variou entre $0,4 \%$ e $14,3 \%$. Os casos humanos de infecção chagásica sorologicamente demostrada pertenciam a grupos etários superiores a 20 anos. Investigação epidemiológica indicou terem estes pacientes sido infectados 
neste Estado quando a transmissão era freqüente ou em outras regiōes do pais onde a doença de Chagas é endêmica?

Nos grupos etários correspondentes a indivíduos jovens, isto é, menos de 20 anos, o encontro de positividade sorológica é infreqüente na fase atual da vigilância ${ }^{2}$. Evidencia-se, então, a necessidade da realização de investigação pormenorizada que permita caracterizar aspectos de transmissão, como as vias mais freqüentes e espaços físicos em que ocorrem. Torna-se, portanto, relevante o relato, no presente trabalho, de encontro recente de caso positivo sorológico em criança.

\section{Apresentação do Caso}

Em outubro de 1988, um morador da zona rural do Município de Itapeva, Micrortegiāo Campos de Itapetininga, Estado de São Paulo, notificou o encontro de um exemplar de triatomíneo identificado como ninfa de terceiro estádio de Panstrongylus megistus, nāo infectado por $T$. cruzi. A reação feita para identificação da fonte de alimento do inseto foi positiva para sangue humano. A pesquisa minuciosa feita no domicilio cortespondente a essa notificação não revelou a presença de outros insetos.

Foram realizados exames sorológicos, por meio de RIFI, em seis habitantes da casa em estudo. Verificou-se positividade em apenas um, uma criança de 8 anos de idade, sexo masculino. Título $=128$ para IgG e negativo para IgM. Esta positividade se confirmou com a utilização de outras técnicas: aglutinação direta e hemaglutinaçāo indireta. Os pais da ctiança e demais moradores da casa revelaram-se negativos para anticorpos anti-T. cruzi.

A mãe do menor informou ser este natural do Município de Itapeva (de onde procedia o exemplar de $P$. megistus referido). Foram negados: existência de chagásicos na familia, conhecimento da existência de "barbeiros" no domicílio ou ocorrência de picadas desses insetos, deslocamento para áreas onde se dá a transmissão natural da infecção ou ainda de caça ou manipulação de seus produtos.

Investigação de seu passado transfusional revelou ter o menor recebido sangue em agosto de 1982, quando contava um ano de idade, e estava internado na Santa Casa de Itapeva, Região de Sorocaba (SP), com diagnóstico de pneumonia. Teve alta logo após a transfusão, o que impediu a obtenção de informações sobre sintomatologia pós-transfusional. Segundo registro no
Hospital, pôde-se constatar que o menor recebeu $160 \mathrm{ml}$ de sangue tipo $A-R h$ positivo e foi identificado o doador. Ainda segundo o Hospital, o doador tinha exame negativo para Chagas.

A Vigilância Epidemiológica do SUDS de Itapeva está atualmente com a responsabilidade do acompanhamento clínico e laboratorial do caso. Presentemente, o paciente está sendo submetido a exames cardiológicos periódicos, não apresentando sinais ou sintomas clínicos até o momento.

\section{Investigação do Doador}

Do sexo masculino, 37 anos de idade, o doador é casado e tem dois filhos considerados saudáveis. É natural de São Paulo (Capital) e reside em área urbana do Município de Itapeva desde 1982. Trabalhou, entre junho de 1988 e maio de 1989 em área urbana do Município de Cotia (Grande São Paulo) como mecânico de automóveis. Retornava à sua residência em Itapeva apenas nos fins de semana. Investigação realizada revelou ter o doador residido, desde os dois anos de idade, em casas de madeira e de pau-a-pique em áreas rurais de municipios onde a infecção chagásica era endêmica, nos Estados de Minas Gerais e São Paulo. A anamnese revelou haver quantidade de "barbeiros" em uma dessas casas. Sabia que a doença relacionada com eles "ataca o coraçāo" e havia tomado conhecimento de um caso de doença de Chagas após a morte de um vizinho seu de Cabreúva (SP). Desconhecia, entretanto, sua condição de infectado chagásico. Doou sangue em quantro oportunidades: em 1971, em Itu (SP), durante o serviço militar; em 1974, em São Paulo (SP), no Hospital da Beneficência Portuguesa; em 1975, em Itu, no Hospital de Itu e em 1982 em Itapeva, na Santa Casa. Esteve internado por três vezes: a primeira por "depressão" (sic), a segunda por pneumonia e a terceira devido a queimaduras no tronco. Nunca recebeu transfusão de sangue ou foi submetido a cirurgia. Sempre exerceu atividades que exigem esforços: na lavoura, dos 7 aos 17 anos; depois em serviços de mercenaria e, atualmente, em mecânica de automóveis.

O doador não apresentava, no momento da investigação, sintomatologia cardíaca ou digestiva; mas foi encaminhado para avaliação clínica junto ao SUDS de Itapeva. Resultados de: exames sorológicos: reação de hemaglutinação indireta, título = 128; teação de aglutinação direta, título = 32; RIFI, título $=1024(\mathrm{IgG})$ e negativa (IgM). 


\section{Comentários}

Deve ser ressaltada a importância de uma investigação epidemiológica em casos como o descrito, no qual foi evidenciada a via de transmissão, que envolve, neste exemplo, o problema do controle de doadores de sangue. Este problema se torna extremamente grave ao observar-se que o paciente já havia doado sangue quatro vezes, em quatro instituiçōes diferentes, sem que se tenha descoberto sua condição de infectado chagásico. Destaque-se a participação do SUDS de Itapeva na avaliação clínica da criança infectada, exemplo a ser estendido a toda a rede básica de saúde que deve estar aparelhada e dimensionada para atender a demanda de encaminhamento de pacientes infectados.

\section{Agradecimentos}

Á pesquisadora Vera Lúcia Pereira do Instituto Dante Pazzanese de Cardiologia de São Paulo, pela realização dos testes de aglutinação direta e de hemaglutinação indireta; ao Prof. Dr. Cláudio Santos Ferreira, do Departamento de Parasitologia do Instituto de Ciências Biomédicas da Universidade de São Paulo, pela revisão crítica do manuscrito.

WANDERLEY, D.M.V. et al. [Transfusional chagasic infection detected during the execution of a program for the control of Chagas' disease in the State of S. Paulo (Brazil)]. Rev. Saúde públ., S. Paulo, 26: 203-5, 1992. A system of surveillance for Chagas' disease aiming at a systematic investigation of the occurrence of triatominae in human dwellings in S. Paulo, Brazil was proposed. It included a serological survey of residents in house considered to be potencial breeding places for blood-sucking triatomines. Serologically positive cases were observed to be distributed in age groups from 19 years of age upwards. Case-investigation revealed that the infection had been acquired either in S. Paulo in the past or recently in other States. A serologically positive (titre $=128-\mathrm{IgG}$ ) case of an 8-year-old male child, was detected by the Indirect Fluorescent Antibody Technique (IFAT). In S. Paulo State natural transmission is now of low probability. An epidemiological investigation disclosed the fact that this was a case of blood transfusion infection. The donor was found to be serologically positive (IFAT, titre = $1024-\mathrm{IgG}$ ). His case-history was typical of vector transmitted infection. It is worthy of note that blood had been donated by this patient in four instances, without his condition having been diagnosed. The necessity of organizing an integrated Public Health Service to take more efficient care of such cases is stressed.

Keywords: Trypanosomiasis South American, transmission. Blood transfusion, adverse effects.

\section{Referências Bibliográficas}

1. BURALLI, G.M. Estudo do controle dos triatomíneos domiciliados no Estado de São Paulo. São Paulo, 1985. [Dissertação de Mestrado - Faculdade de Saúde Pública da USP].

2. CARVALHO, M.E de; WANDERLEY, D.M.V.; ALMEDA, M.C.R.R. de Sorologia de infeç̧ão chagásica em áreas restritas de focos de triatomineos vetores no Estado de Sảo Paulo. Rev. Soc. bras. Med. Trop., 20(supl. 2): 5, 1987. [Apresentado à 4' Reuniāo Anual sobre Pesquisa Aplicada em Doença de Chagas, Araxá, 1987 Resumo].

3. SOUZA, A.G.; BURALLI, G.M.; WANDERLEY, D.M.V.; ANDRADE, J.C.R. de Consolidation of the control of Chagas' disease vectors in the State of São Paulo. Mem. Inst. Oswaldo Cruz Rio de Janeiro, 79(supl.): 125-31, 1984.

4. WANDERLEY, D.M.V. Análise da atual estratégia do Programa de Controle da doença de Chagas no Estado de Săo Paulo. Sāo Paulo, 1987. [Dissertação de Mestrado - Faculdade de Saúde Pública da USP].

Recebido para publicação em 29/8/1991

Reapresentado em 24/3/1992 Aprovado para publicaçāo em 16/4/1992 